\title{
Hyperalgesia during Acute Opioid Abstinence: Evidence for a Nociceptive Facilitating Function of the Rostral Ventromedial Medulla
}

\author{
Hilary Kaplan and Howard L. Fields \\ Departments of Neurology and Physiology and Keck Center for Integrative Neuroscience, University of California, \\ San Francisco, California 94143
}

\begin{abstract}
Naloxone-precipitated opioid abstinence is associated with enhancement of reflex responses to noxious stimulation (hyperalgesia). The present experiments in lightly anesthetized rats were designed to determine (1) whether neurons in the rostral ventromedial medulla (RVM) contribute to this enhancement, and (2) whether this enhancement is due to removal of an inhibitory modulatory influence or to activation of a facilitatory influence. In the first experiment, $10 \mu \mathrm{g}$ of morphine was microinjected into the RVM; subsequent administration of naloxone (1 $\mathrm{mg} / \mathrm{kg}$, i.v.) shortened tail-flick latency. This is evidence that a synaptic action of opioids within the RVM can contribute to hyperalgesia. In the second experiment, systemic administration of morphine $(2 \mathrm{mg} / \mathrm{kg}$, i.v.) was followed by systemic administration of naloxone ( 1 $\mathbf{m g} / \mathbf{k g}$, i.v.), which produced a significant hyperalgesia that could be markedly attenuated by microinjection of $10 \mu \mathrm{g}$ lidocaine into the RVM. That inactivation of RVM reduces the hyperalgesia indicates that the CNS is capable of generating a facilitating action on nociceptive transmission. Previous studies from this laboratory have indicated that a population of RVM neurons, on-cells, shows increased activity during opioid abstinence. The present experiments support the hypothesis that RVM on-cells exert a facilitating influence on nociceptive transmission.
\end{abstract}

Opioids produce potent analgesia in humans, and in animals, they increase the threshold for reflex responses to noxious stimuli. These antinociceptive effects occur whether opioids are given systemically (Fields, 1985), intrathecally (Yaksh, 1981), or supraspinally (Yeung and Rudy, 1980; Yaksh et al., 1988). Conversely, when opioid administration is either abruptly terminated or followed by administration of an antagonist, an abstinence syndrome appears during which human subjects report spontaneous pain (Jaffe, 1985; Heishman et al., 1989), and in animals there is an enhancement of reflex responses to noxious stimuli (Kayan et al., 1971; Kosersky et al., 1974; Bickel et al., 1988). The hyperalgesia observed during opioid abstinence could result from reduction of a tonic inhibitory modulation that was present prior to drug administration. An important alternative,

\footnotetext{
Received June 22, 1990; revised Dec. 10, 1990; accepted Dec. 26, 1990.

We thank Lael Carlson, Beth Budra, Mike Morgan, Peggy Mason, Mary Kay Floeter, and Mary Heinricher. This work was supported by NIDA 01949 and by a grant from the Bristol-Myers Squibb Foundation.

Correspondence should be addressed to Howard L. Fields, Box 0114, Neurology,

UCSF, San Francisco, CA 94143.

Copyright (C) 1991 Society for Neuroscience 0270-6474/91/111433-07\$03.00/0
}

however, is that it is the consequence of the activation of modulatory neurons that facilitate nociceptive transmission.

An extensive body of evidence has implicated neurons in specific brainstem sites in nociceptive modulation (Basbaum and Fields, 1984; Fields et al., 1988; Willis, 1988). Neurons in the rostral ventromedial medulla (RVM), which includes the nucleus raphe magnus, nucleus gigantocellularis pars alpha, and the adjacent reticular formation, are of particular interest, because they are part of a well-established pathway for nociceptive modulation. The RVM projects densely to spinal and trigeminal dorsal horn laminae containing neurons implicated in nociceptive transmission, and electrical stimulation of or glutamate microinjected into the RVM elicits antinociceptive effects (Basbaum and Fields, 1984). There is also evidence that the RVM plays an important role in opioid modulation of nociception. Microinjection of opioids into the RVM produces naloxonereversible antinociception, and lesions of or naloxone injections into the RVM reduce the effectiveness of systemically administered morphine (Proudfit and Anderson, 1975; Akaike et al., 1978; Dickenson et al., 1979; Azami et al., 1982; Jensen and Yaksh, 1986).

Most of the experimental observations on this brainstem-todorsal horn modulatory pathway have focused on its inhibitory actions on nociceptive transmission (e.g., Basbaum and Fields, 1984). Recent experiments, however, have raised the possibility that this pathway also has a facilitating action on nociception. Light et al. (1986) have shown that electrical stimulation of RVM can cause an early depolarization in some dorsal horn nociceptive neurons. Although dorsal horn neurons excited by stimulation of brainstem modulatory regions may be inhibitory interneurons, Zhuo and Gebhart (1990) have recently reported that low-intensity electrical stimulation of RVM shortens the latency to tail flick (TF) evoked by noxious heat. In addition, enhancement of nocifensor responses can be produced in opioiddependent animals by naloxone microinjected into the periaqueductal gray (PAG; Wilcox et al., 1979), a region that projects indirectly to the spinal cord dorsal horn by way of the RVM (Behbehani and Fields, 1979; Abols and Basbaum, 1981; Beitz et al., 1983). Because opioid microinjection into the PAG concomitantly affects RVM neuronal firing and reflex responses to noxious stimulation (Cheng et al., 1986), it is possible that the hyperalgesic effect generated by neurons in the PAG during opioid abstinence is exerted via the RVM.

In the present studies, the possibility that RVM can generate or relay a facilitating effect on nociceptive transmission was investigated by microinjecting morphine into RVM and then inducing withdrawal by systemic administration of naloxone. 


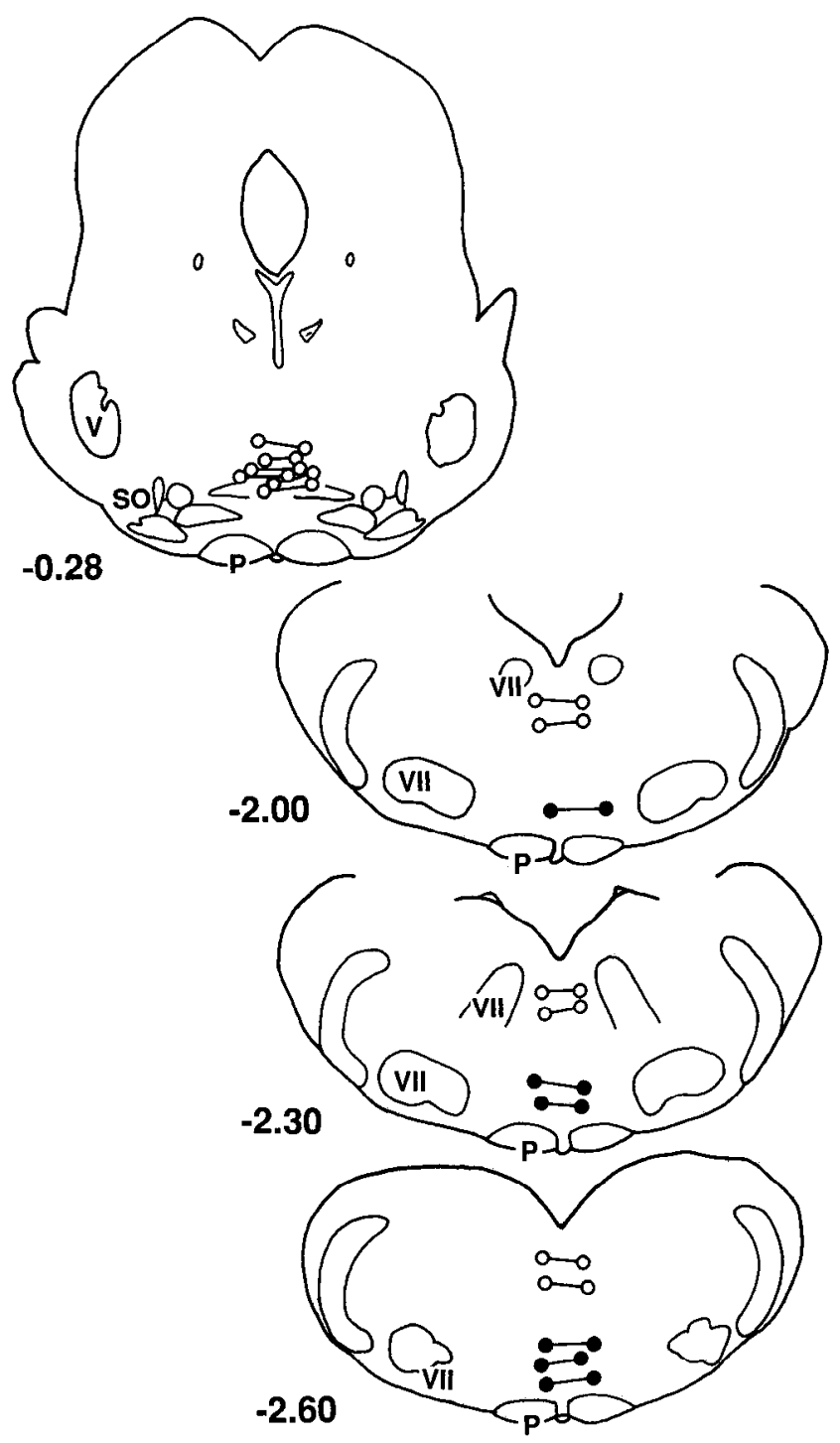

Figure 1. Paired injection sites for morphine are shown. Solid circles represent sites where bilateral morphine microinjection $(5.0 \mu \mathrm{g} / 0.5 \mu \mathrm{l})$ produced antinociception, and in all rats the subsequent systemic administration of naloxone $(1 \mathrm{mg} / \mathrm{kg})$ resulted in hyperalgesia. Open circles represent sites where the bilateral microinjection of morphine did not produce antinociception, and in these rats the subsequent administration of naloxone did not affect TF latency.

Significant shortening of TF latency was observed, suggesting that the RVM can contribute to the hyperalgesia of opioid abstinence. However, because an enhancement of nociceptive transmission could result from direct facilitation or loss of inhibition, this experiment left open the question of whether neurons in the RVM are capable of generating an active facilitation. The second experiment was designed to address this question by microinjecting lidocaine into the RVM to diminish all neural activity and thus remove the output of the RVM. During naloxone-precipitated opioid withdrawal, lidocaine microinjected in RVM decreased nociceptive responsiveness (i.e., reduced the hyperalgesia), thus supporting the presence of a distinct nociceptive facilitatory output from the RVM.

\section{Materials and Methods}

Animals. Male Sprague-Dawley rats weighing 250-275 gm were initially anesthetized with sodium pentobarbital $(60 \mathrm{mg} / \mathrm{kg}$, i.p.). A catheter was

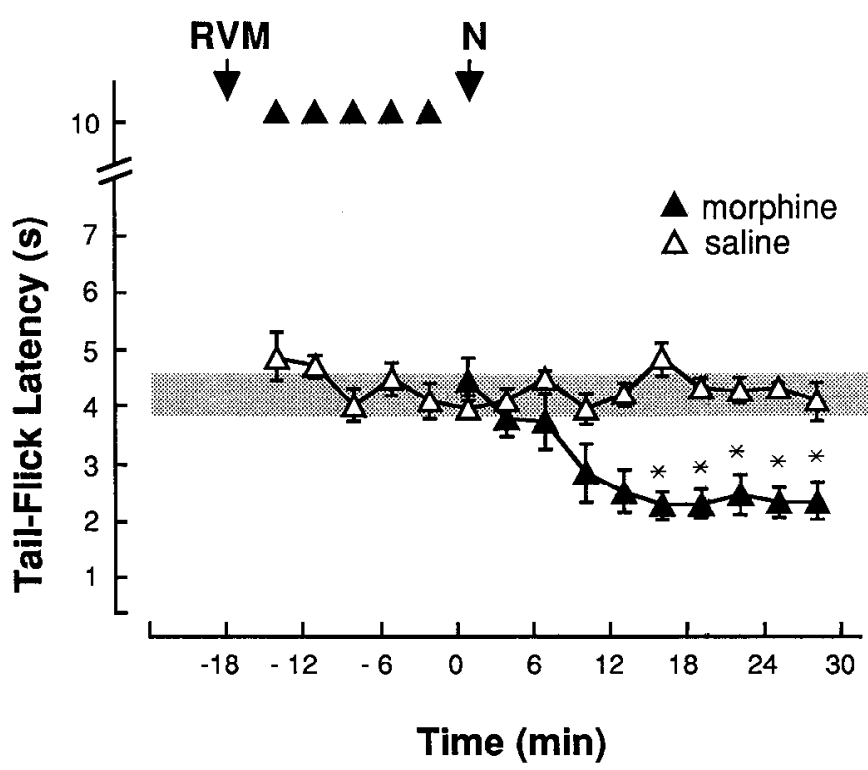

Figure 2. Naloxone administered following morphine microinjected into RVM produces an acute abstinence syndrome. Following five baseline TF trials (shaded band indicates mean \pm SEM), morphine $(5 \mu \mathrm{g} /$ $0.5 \mu \mathrm{l}$; solid triangles) or saline (open triangles) was microinjected on each side of the $R V M$ (at arrow). The subsequent administration of naloxone $(1 \mathrm{mg} / \mathrm{kg}$, i.v.), at $N$, resulted in a significant decrease in TF latency in the morphine-treated animals, but no change in TF latency of the opioid-naive animals. ${ }^{*}, p<0.05$.

placed in each external jugular vein. The animal was then placed in a stereotaxic frame, and a small craniotomy was drilled posterior to the lambdoidal suture. Two 25-gauge stainless-steel guide cannulas separated by $0.5 \mathrm{~mm}$ in the coronal plane were lowered towards the RVM. Body temperature was stabilized throughout the experiments by a circulating water blanket maintained at $37^{\circ} \mathrm{C}$.

The animal was then allowed to recover from the initial anesthetic until a tail-flick reflex could be elicited in response to noxious heat. A continuous infusion of methohexital $(15-30 \mathrm{mg} / \mathrm{kg} / \mathrm{hr}$, i.v.) was then started. The animal was thus maintained in a lightly anesthetized state with no obvious signs of discomfort. Nociceptive testing was initiated $45 \mathrm{~min}$ after starting the methohexital infusion.

Intracerebral microinjections were made into the RVM with two 31gauge injection cannulas attached to polyethylene tubing (PE 20) connected to 1.0- $\mu 1$ Hamilton syringes. The injection cannulas were inserted into the RVM before the initiation of behavioral testing and were left in place for the duration of the experiment. The progress of the injection was monitored via the movement of an air bubble through the tubing.

Drugs. In the first series of experiments, either morphine or saline $(0.9 \%)$ was microinjected into the RVM. A volume of $0.5 \mu \mathrm{l}$ was simultaneously microinjected on each side of the midline $(5 \mu \mathrm{g}$ of morphine was injected on each side). Twenty-five minutes later, naloxone $(1 \mathrm{mg} / \mathrm{kg}$ ) was administered intravenously. Microinjections of morphine were also made either dorsal or rostral to RVM as placement controls.

In the second series of experiments, morphine $(2 \mathrm{mg} / \mathrm{kg})$ or saline was injected intravenously. Naloxone was administered 25 min later (1 $\mathrm{mg} / \mathrm{kg}$, i.v., in $0.3 \mathrm{ml}$ ). The doses of morphine and naloxone that were selected were those that were previously established in this laboratory to induce a maximal hyperalgesic response in lightly anesthetized rats (Kim et al., 1990). All injections were followed by a 0.8-ml saline flush of the catheter.

Four minutes following the administration of naloxone, either $0.5 \mu 1$ saline $(0.9 \%)$ or $10 \mu \mathrm{g}$ lidocaine in the same volume of saline was microinjected into each side of the RVM over a 2 -min period. The dose of lidocaine selected was known to decrease the threshold to elicit a nocifensive reflex when microinjected into RVM in lightly anesthetized, opioid-naive rats (M. Morgan, unpublished observations). Control microinjections were also made either dorsal or rostral to RVM.

Nociceptive testing. The tail-flick reflex evoked by noxious heat was used as the index of nociceptive responsiveness. The stimulus was a 
linear temperature ramp that rose from a holding temperature of $35^{\circ} \mathrm{C}$ to $52^{\circ} \mathrm{C}$ in $10 \mathrm{sec}$. A small thermistor probe was placed in contact with the heated site on the blackened ventral surface of the tail and provided a signal for the feedback-controlled projection lamp. The heat was automatically terminated at $10 \mathrm{sec}$ or upon occurrence of a flick. Tail-flick (TF) trials were initiated every $3 \mathrm{~min}$ at three tail sites 3,5 , and $7 \mathrm{~cm}$ from the distal tip of the tail, used in rotation. The baseline tail-flick latency was taken as the average latency of the last three of five TF trials. Following the first intravenous drug injection, there was a 10min hiatus in testing.

For the purpose of this paper, the term "hyperalgesia" will be used to denote a shortening of TF latency below the premorphine baseline level. The use of this term does not imply a specific mechanism, nor is it meant to imply that the rats actually feel greater pain.

An external temperature probe (YSI 427) was taped $4 \mathrm{~cm}$ from the base of the tail on the ventral surface to allow constant monitoring of tail-skin temperature (TS temp) proximal to the site of the heat stimulus used to evoke the TF. This was necessary because Katovich et al. (1987) have demonstrated that there is a surge in rat TS temp, as well as a decrease in core body temperature, during systemic naloxone-precipitated opioid withdrawal. Because a change in this parameter could affect the TF latency (Ness and Gebhart, 1986; Eide and Rosland, 1989), the TS temp was monitored by both the thermistor probe controlling the heat stimulus and a more proximal skin temperature probe.

Histology. At the end of the experiment, the animal was killed with an overdose of methohexital and intracardially perfused first with saline, then with $10 \%$ formalin. The sites of all injection cannulas were verified histologically.

Statistical analysis. Tail-flick latency is presented as mean and standard error of the mean (SEM). Differences between groups were determined using a repeated-measures analysis of variance (ANOVA) followed by Tukcy's post hoc analysis. TS temp is reported as mean and SEM and absolute range of temperature where appropriate. TS temp data were analyzed with a repeated-measures ANOVA and Tukey's post hoc analysis.

\section{Results}

\section{Experiment 1}

The first series of experiments addressed the contribution of the RVM to the hyperalgesia that is part of the naloxone-precipitated opioid-abstinence syndrome. Either saline $(n=6)$ or 10 $\mu \mathrm{g}$ morphine $(n=6)$ was microinjected into the RVM (see Fig. 1 for locations). The effect of the subsequent intravenous administration of naloxone on TF latency and proximal tail temperature was studied (Fig. 2). ANOVA revealed significant differences between groups $(F=50.4 ; p<0.01)$ and between trials $(F=13.7 ; p<0.01)$. The mean baseline TF latency for the RVM saline group was $4.8 \pm 0.18 \mathrm{sec}$, and for the RVM morphine group, it was $4.7 \pm 0.17 \mathrm{sec}$, with no significant difference between the two groups (Tukey, $p>0.05$ ). Neither microinjection of saline into the RVM nor administration of intravenous naloxone after RVM saline produced a significant change in the TF latency compared to basclinc (Tukcy, $p>0.05$ ).

The six rats that received morphine into the RVM exhibited an increase in TF latency to the 10-sec cutoff time following the microinjection. In these rats the subsequent administration of naloxone resulted in a reduction of the TF latency to below baseline (i.e., hyperalgesia). At 15 min postnaloxone, the mean latency was $2.3 \pm 0.17 \mathrm{sec}$. This was significantly lower than the premorphine baseline latency (Tukey, $p<0.01$ ) and was significantly lower at the same postnaloxone time point than the $4.6 \pm 0.2-\mathrm{sec}$ mean TF latency of the rats that had received RVM microinjection of saline (Tukey, $p<0.01$; Fig. 2).

In 12 rats, morphine was microinjected outside the area of the RVM (Fig. 1). The mean baseline TF latency was $4.8 \pm$ $0.17 \mathrm{sec}$, which was not different from the baselines of the other two groups of rats in this series of experiments. In these 12 rats, morphine produced no change in TF latency, nor did the sub-

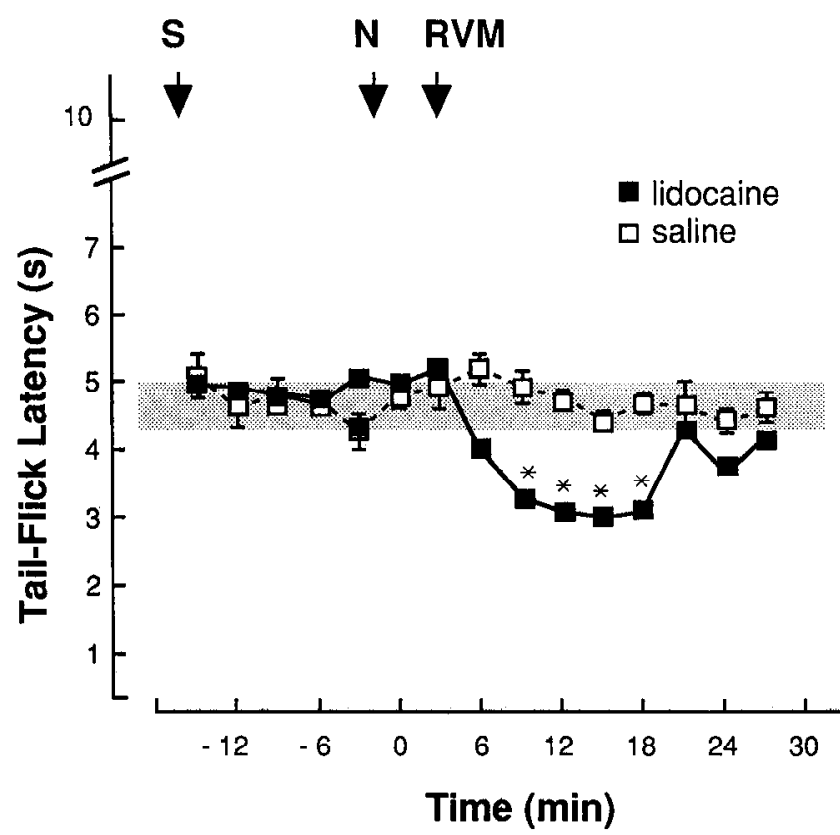

Figure 3. Effect of lidocaine microinjected into RVM of opioid-naive rats. All rats received systemic saline, at $S$, followed by naloxone ( $1 \mathrm{mg} /$ $\mathrm{kg}, \mathrm{i} . \mathrm{v}$.) at $N$. Lidocaine $(10 \mu \mathrm{g} / 0.5 \mu \mathrm{l}$; solid squares) or saline (open squares) was microinjected bilaterally into the $R V M$ (at arrow) $4 \mathrm{~min}$ following naloxone. Shaded band represents mean \pm SEM. Lidocaine. in the RVM caused a significant decrease in TF latency. ${ }^{*}, p<0.05$.

sequent administration of naloxone result in TF facilitation. Thus, the occurrence of the hypcralgesia appcars to depend on injection of morphine into sites that are capable of blocking the TF response.

\section{Tail-skin temperature}

Naloxone given after morphine microinjection into the RVM did not cause a significant change in the TS temp across trials $(F=1.6 ; p>0.05)$ оr compared to rats receiving naloxone after saline microinjected into the $\operatorname{RVM}(F=1.8 ; p>0.05)$.

\section{Experiment 2}

The second series of experiments addressed the contribution of the RVM to the hyperalgesia associated with naloxone-precipitated withdrawal from systemically administered morphine. ANOVA on TF latencies revealed significant differences between groups $(F=62.4 ; p<0.01)$ and between trials $(F=45.4$; $p<0.01)$. The bascline TF latency for the four groups in the second series ranged from 4.5 to $4.8 \mathrm{sec}$, with no significant differences between the four groups (Tukey, $p>0.05$ ). Differences in TF latency were first seen following naloxone administration. Rats receiving naloxone after morphine had significantly shorter TF latencies than saline-pretreated rats receiving naloxone (Tukey, $p<0.05$ ). In those rats receiving intravenous saline as their first drug (Table 1 , groups I, II), the TF latency did not differ from baseline. Furthermore, in these rats, the TF latency was not changed by intravenous naloxone.

\section{Lidocaine in RVM}

Lidocaine $(10 \mu \mathrm{g})$ microinjected bilaterally into the RVM of rats that had not received morphine resulted in a decrease in TF latency to $67 \%$ of baseline (Table 1 , group II). This hyperalgesia was maximal at 7-13 min following the microinjection (Fig. 3). 


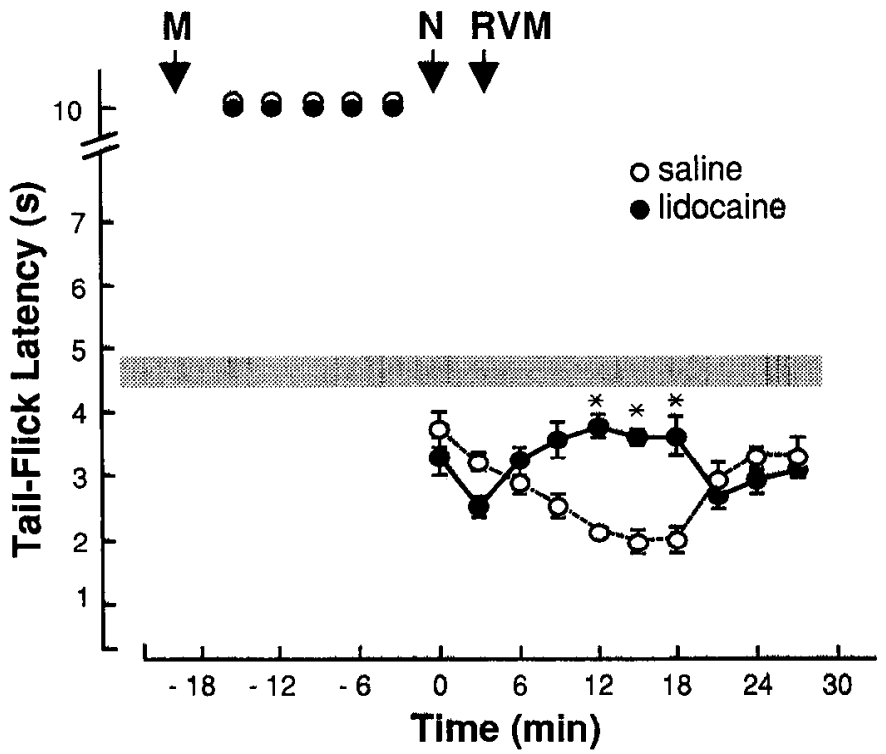

Figure 4. Effect of lidocaine microinjected into the RVM on the hyperalgesia of naloxone-precipitated opioid withdrawal. All rats received morphine ( $2 \mathrm{mg} / \mathrm{kg}$, i.v.), at $M$, followed by naloxone ( $1 \mathrm{mg} / \mathrm{kg}, \mathrm{i} . \mathrm{v}$.), at $N$. Subsequently, either lidocaine $(10 \mu \mathrm{g} / 0.5 \mu \mathrm{l}$; solid circles $)$ or saline (open circles) was microinjected bilaterally into the $R V M$ (at arrow). Shaded band represents mean \pm SEM. Lidocaine in the RVM attenuated the hyperalgesia of acute opioid abstinence. ${ }^{*}, p<0.05$.

In contrast, no decrease in TF latency was observed in similarly treated rats that received saline microinjected into the RVM (Table 1, group I). The difference between these two groups was significant (Tukey, $p<0.01$ ).

There were significant changes in TS temp in the four groups of this experiment $(F=22.3 ; p<0.01)$. However, groups of rats receiving intravenous saline (groups I and II) showed only minor increases in TS temp $\left(0.5 \pm 0.2^{\circ} \mathrm{C}\right)$ and did not differ significantly from each other at any time point (Tukey, $p>$ $0.05)$.

\section{Systemic naloxone following systemic morphine}

Intravenous administration of morphine resulted in an increase in the TF latency to the 10-sec cutoff time in all rats (Table 1, groups III, IV). The systemic administration of naloxone following intravenous morphine resulted in a significant decrease in TF latency from baseline (i.e., hyperalgesia) in these two groups at $3 \mathrm{~min}$ postnaloxone. In group III, saline was microinjected into the RVM. In this group, the peak of the hyperalgesia was $10-19$ min following administration of naloxone (Fig. 4, open circles).

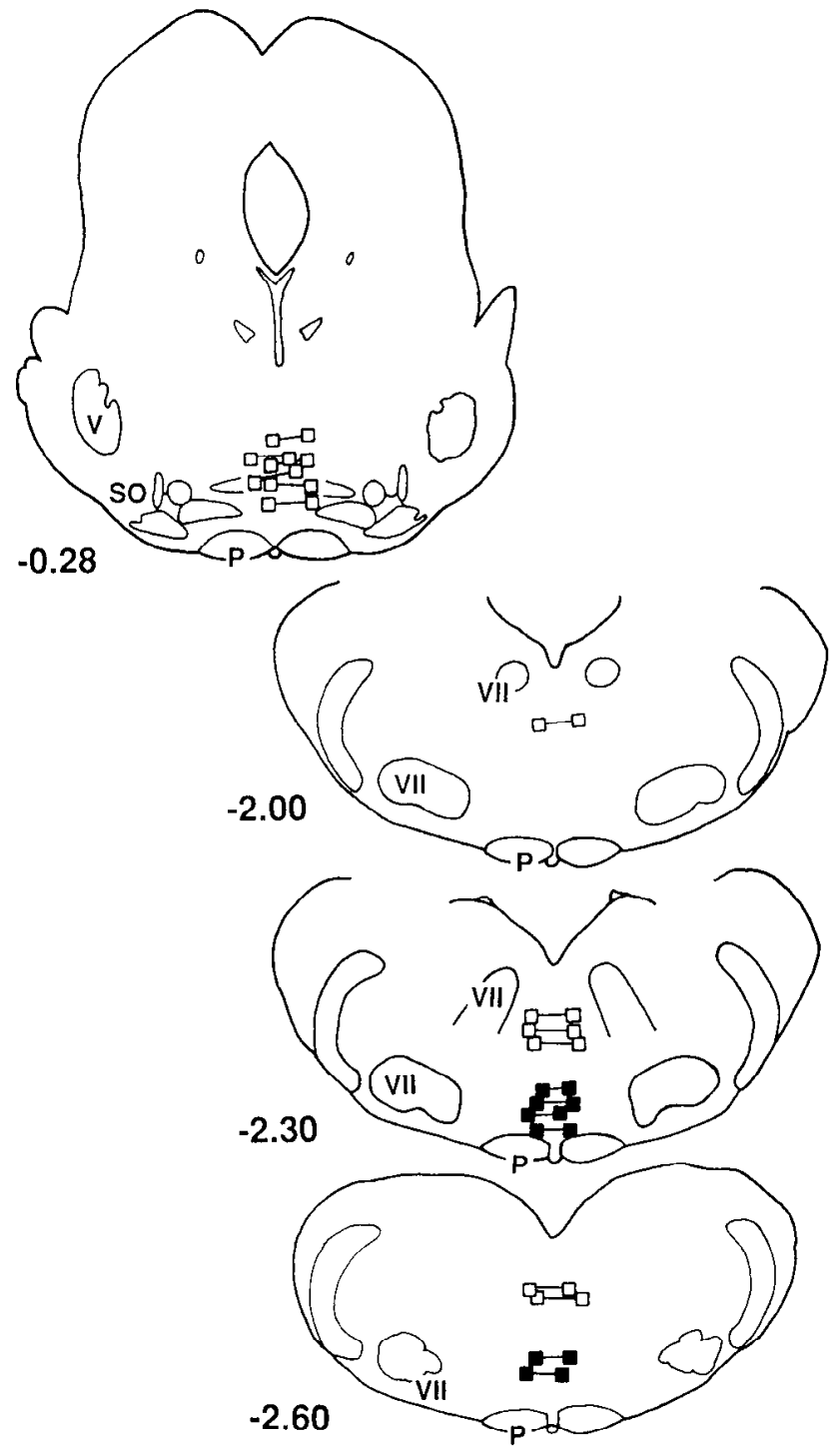

Figure 5. Paired microinjected sites for lidocaine are shown. Rats given systemic morphine $(2 \mathrm{mg} / \mathrm{kg})$ followed by systemic naloxone (1 $\mathrm{mg} / \mathrm{kg}$ ) displayed a significant decrease in TF latency (hyperalgesia). Solid squares represent sites where the bilateral microinjection of lidocaine significantly attenuated the hyperalgesia of acute opioid abstinence. Open squares represent sites of lidocaine microinjections that were ineffective in attenuating the hyperalgesia.

During naloxone-precipitated morphine withdrawal, the TS temp increased an average of $3.5^{\circ} \mathrm{C}$ (from an initial temperature range of $22-26^{\circ} \mathrm{C}$ to a maximum temperature ranging from $26^{\circ} \mathrm{C}$ to $30^{\circ} \mathrm{C}$; ; this is below the $35^{\circ} \mathrm{C}$ holding temperature of the

Table 1. Lidocaine microinjected into the RVM attenuates the hyperalgesia of acute opioid abstinence

\begin{tabular}{llllllll} 
Group & Baseline & $\begin{array}{l}\text { Systemic } \\
\text { injection }\end{array}$ & $\begin{array}{l}\text { Fifteen minutes } \\
\text { postinjection }\end{array}$ & $\begin{array}{l}\text { Systemic } \\
\text { injection }\end{array}$ & $\begin{array}{l}\text { Three minutes } \\
\text { postnaloxone }\end{array}$ & $\begin{array}{l}\text { Micro- } \\
\text { injection } \\
\text { into RVM }\end{array}$ & $\begin{array}{l}\text { Fifteen minutes } \\
\text { postnaloxone }\end{array}$ \\
\hline I & $4.6 \pm 0.13$ & S & $4.6 \pm 0.22$ & $\mathrm{~N}$ & $5.0 \pm 0.27$ & $\mathrm{~S}$ & $4.5 \pm 0.11$ \\
II & $4.6 \pm 0.14$ & $\mathrm{~S}$ & $4.7 \pm 0.15$ & $\mathrm{~N}$ & $4.7 \pm 0.28$ & $\mathrm{~L}$ & $3.1 \pm 0.14$ \\
III & $4.7 \pm 0.22$ & $\mathrm{M}$ & $10+$ & $\mathrm{N}$ & $3.3 \pm 0.13$ & $\mathrm{~S}$ & $2.1 \pm 0.12$ \\
IV & $4.5 \pm 0.18$ & $\mathrm{M}$ & $10+$ & $\mathrm{N}$ & $2.5 \pm 0.17$ & $\mathrm{~L}$ & $3.7 \pm 0.11$ \\
\hline
\end{tabular}

$n=6$ in all groups.

M, morphine sulfate ( $2 \mathrm{mg} / \mathrm{kg}$, i.v.); $\mathrm{S}, 0.9 \%$ saline; N, naloxone ( $1 \mathrm{mg} / \mathrm{kg}$, i.v.); L, lidocaine $(10 \mu \mathrm{g} / 0.5 \mu \mathrm{l})$ bilaterally into RVM. 
thermal stimulator used to elicit the TF. Only animals that received intravenous morphine followed by intravenous naloxone exhibited significant changes in TS temp compared to their baseline values (Tukey, $p<0.05$ ). Rats that received intravenous naloxone following intravenous saline showed no changes in TS temp compared to baseline (Tukey, NS).

\section{Effect of lidocaine on the hyperalgesia of acute opioid abstinence}

Lidocaine microinjected bilaterally into the RVM caused a significant attenuation of the hyperalgesia of animals that had received intravenous morphine followed by intravenous naloxone (see Table 1, group IV). At $15 \mathrm{~min}$ following administration of naloxone, rats that received lidocaine in the RVM had a mean TF latency of $3.8 \pm 0.11 \mathrm{sec}$; at this time, rats that had received a microinjection of saline had a significantly shorter TF latency of $2.1 \pm 0.12 \mathrm{sec}$ (Tukey, $p<0.05$; Fig. 4). The hyperalgesia reducing effect of the lidocaine was maximal 7-13 $\mathrm{min}$ following the RVM microinjection.

When the lidocaine was microinjected outside the boundaries of the RVM (Fig. 5), either $2 \mathrm{~mm}$ dorsal in the medial longitudinal fasciculus $(n=6)$ or $2 \mathrm{~mm}$ rostral (i.e., at the rostral pole of the superior olive; $n=6$ ) in animals that had received intravenous morphine followed by intravenous naloxone, the hyperalgesia was not attenuated. The TF latency did not differ significantly from that observed in similarly treated rats that received saline microinjected into the $\operatorname{RVM}(F=2.7 ; p>0.05)$.

Despite the attenuation of the hyperalgesia by RVM lidocaine, the surge in TS temp produced by intravenous naloxone in rats receiving intravenous morphine was not reduced by the $\mathrm{mi}$ croinjection of lidocaine into RVM (Tukey, $p>0.05$ ).

\section{Discussion}

The present experiments have demonstrated that lidocaine microinjected into the RVM reduces the enhanced response to noxious stimuli that occurs during opioid abstinence. This observation directly implicates the RVM in a supraspinal modulatory network that is capable of generating an active facilitation of responses to noxious stimuli.

\section{Skin temperature during opioid abstinence}

The administration of naloxone to animals that had received systemic morphine caused a surge in TS temp during the period of naloxone-precipitated withdrawal. In the present experiments, the changes in TS temp were less than that previously reported (Katovich et al., 1987), and it appears unlikely that these changes significantly affected TF latency in the current experiments. First, despite the small increases in proximal TS temp, the $35^{\circ} \mathrm{C}$ holding temp of the TF apparatus is above the peak TS temp observed during naloxone-induced abstinence, thus ensuring that all imposed thermal stimuli began from the same baseline. Second, rats with different TS temp, as measured at a site remote from the tail area heated, exhibited similar TF latencies. For example, animals that received RVM microinjection of morphine and animals that received systemic morphine exhibited similar degrees of hyperalgesia following administration of naloxone; however, only the latter group exhibited any changes in TS temp. Therefore, the changes in TS temp that occur during the naloxone-precipitated abstinence syndrome do not contribute significantly to the observed shortening of TF latency. This not only confirms the independence of the proximal TS temp and the hyperalgesia, but also indicates that the
RVM does not contribute to the temperature increase observed during naloxone-precipitated opioid abstinence.

\section{Evidence for a nociceptive facilitating output from RVM}

The present studies confirm previous observations that opioid abstinence is associated with enhanced responsiveness to noxious stimuli (Wilcox et al., 1979; Kim et al., 1990). This enhancement could result from active facilitation or removal of inhibition of nociceptive transmission or both. If the enhancement resulted from an RVM facilitatory effect on nociceptive transmission, then it should be attenuated by the removal of the RVM output during withdrawal. If, on the other hand, the enhancement were due solely to removal of an inhibitory influence, then inactivation of the RVM during abstinence should either have no additional effect or further increase the hyperalgesia. Because it is markedly attenuated by lidocaine in the RVM, the hyperalgesia of opioid abstinence is due to activation of a facilitating output. A corollary of this is that the RVM is capable of generating an output that increases responsiveness to noxious stimulation. Although lidocaine affects both neurons and fibers of passage, the fact that hyperalgesia can be produced by naloxone after morphine microinjected into RVM supports the idea that RVM neurons facilitate nociceptive transmission. The use of drugs such as GABA agonists to inactivate selectively RVM neurons might be helpful to define further the contribution of RVM neurons versus fibers of passage.

It is possible that the nocifensor reflex enhancement observed during opioid abstinence actually reflects facilitation of motoneurons rather than a specific effect upon dorsal horn interneurons involved in nociceptive transmission. Although the rostral RVM projects specifically to dorsal horn and autonomic nuclei, and the nociceptive modulatory pathway running from the PAG to RVM to spinal cord is not known to affect motoneurons directly, the observed increased responses could derive from drug effects upon nearby nuclei (such as nucleus raphe pallidus) that project directly to the ventral horn. Specific studies will be required to resolve this issue.

\section{Opposing effects of lidocaine in opioid-naive and opioid- dependent rats}

As discussed above, lidocaine injected into the RVM during opioid abstinence reduces responsiveness to noxious stimulation. In contrast, the present experiments have confirmed the previous observations that, in opioid-naive rats, inactivation of RVM neurons by lesions or local anesthetic enhances responsiveness to noxious stimulation (Proudfit, 1975, 1980; Sandkuhler and Gebhart, 1984). The opposing effects of inactivation of RVM neurons are most simply explained by assuming that the output of RVM differs under these two conditions. In other words, in opioid-abstinent rats, the net output of RVM is facilitatory; thus, inactivation of RVM reduces behavioral responses to noxious stimulation. In opioid-naive rats, the net output of RVM is inhibitory, and thus inactivation of RVM results in enhancement of responses to noxious stimulation. These assumptions receive support from physiological studies of RVM neurons under conditions similar to those of the present experiments (Bederson et al., 1990).

\section{The role of specific classes of $R V M$ neurons in nociceptive inhibition and facilitation}

Electrophysiologic experiments in the lightly anesthetized rat have demonstrated that there are two classes of cells in the RVM 
whose activity is correlated with nocifensor reflexes (Fields et al., 1988). One class is consistently inhibited by stimuli in the noxious range applied over wide areas of the body surface. The firing of this cell class abruptly slows just prior to the occurrence of a withdrawal reflex. This cell class, termed the "off-cell," fires continuously following administration of morphine in doses that block nocifensive reflexes (Fields et al., 1983, 1988). The second class of cell exhibits a firing pattern reciprocal to that of the offcell and is called the "on-cell" (Barbaro et al., 1986, 1989; Oliveras et al., 1989). The on-cell bursts prior to reflexes elicited by noxious stimuli and is inhibited by morphine.

There is independent evidence correlating the spontaneous firing of a given RVM cell class with changes in the TF latency. In the lightly anesthetized rat, all cells of each physiological class show tightly correlated periods of activity (Barbaro et al., 1989). Heinricher et al. (1989) have demonstrated that, if noxious heat is applied during a period of on-cell activity, the TF latency is significantly shorter than if the same stimulus is given during a period of off-cell activity.

Electrical stimulation or the microinjection of glutamate in the RVM usually results in antinociception (Zorman et al., 1981; Satoh et al., 1983; Jensen and Yaksh, 1984). These manipulations should have only direct excitatory effects on RVM neurons, which implies that there is a class of RVM neurons whose activity leads to inhibition of nociceptive transmission at the spinal cord. Several lines of evidence support the hypothesis that the off-cell is the RVM inhibitory output cell (for review, see Fields et al., 1988).

During naloxone-precipitated opioid withdrawal, off-cells are silent or relatively inactive, while on-cell firing is markedly increased (Bedcrson et al., 1990). This increase in on-cell activity during opioid withdrawal was shown to be correlated in both time and magnitude with an increase in reflex responses to noxious input (hyperalgesia). Because the hyperalgesia of the opioid-abstinence syndrome is blocked by inactivation of the RVM, it is likely that some neural element within RVM actively facilitates nociceptive transmission. Because off-cells are relatively silent and on-cells show increased activity during opioid abstinence, the present results are consistent with the conclusion that the reduction of hyperalgesia by RVM lidocaine is due to its inactivation of the on-cell. Although inactivation of fibers of passage or some other, unidentified nerve cell class within RVM could account for the lidocaine effect, the present data support the hypothesis that on-cells provide a functional output from the RVM that is facilitatory to nocifensor reflexes.

\section{Nociceptive modulating pathways may contribute to the hyperalgesia of opioid abstinence}

It is generally accepted that neurons in the brainstem contribute to the antinociceptive actions of systemically administered opioids (Dickenson et al., 1979; Azami et al., 1982; Fields, 1985; Jensen and Yaksh, 1986). The present observation that, following morphine microinjection into the RVM, systemic naloxone facilitates nocifensor reflexes suggests that neurons in the RVM also contribute to the hyperalgesia of the opioid-abstinence syndrome. Although there is obviously much more to the opioidabstinence syndrome than hyperalgesia (Ritzman, 1981; Jaffe, 1985), the reduction by RVM lidocaine of the hyperalgesia observed when systemic naloxone is given following systemic morphine suggests that changes in the nociceptive modulatory pathway are an important part of the mechanism of acute physical dependence. Support for this concept comes from an observa- tion by Bozarth and Wise (1984), who found that systemic naloxone can induce an abstinence syndrome (including escape behavior) in rats after infusion of morphine into the PAG area. In addition, Wilcox et al. (1979) found that naloxone microinjected into the PAG can induce hyperalgesia in rats made physically dependent by systemic morphine.

An interesting implication of the present findings is that facilitation of nociceptive transmission may contributc to the aversiveness of opioid withdrawal. In other words, the hyperresponsiveness during opioid abstinence that is observed in animals may be a meaningful correlate of increased perceived pain intensity and/or an aversive signal. In unanesthetized rats, naloxone injected into the PAG region of opioid-tolerant rats results in escape behavior (Wei and Loh, 1976; Wilcox et al., 1979), and in human subjects, increased reports of pain are a common feature of the opioid-abstinence syndrome (Jaffe, 1985; Heishman et al., 1989).

\section{References}

Abols IA, Basbaum AI (1981) Afferent connections of the nostral medulla of the cat: a neural substrate for mid-brain-medullary interactions. J Comp Neurol 201:285-297.

Akaike A, Shibata T, Satoh M, Takagi H (1978) Analgesia induced by microinjection of morphine into, and electrical stimulation of, the nucleus reticularis paragigantocellularis of rat medulla oblongata. Neuropharmacology 17:775-778.

Azami J, Llewelyn MD, Roberts (1982) The contribution of nucleus reticularis paragigantocellularis and nucleus raphe magnus to the analgesia produced by systemically administered morphine, investigated with the microinjection technique. Pain 12:229-246.

Barbaro NM, Heinricher MM, Fields HL (1986) Putative pain modulating neurons in the rostral ventral medulla: reflex-related activity predicts effects of morphine. Brain Res 366:203-210.

Barbaro NM, Heinricher MM, Fields HL (1989) Putative nociceptive modulatory neurons in the rostral ventromedial medulla of the rat display highly correlated firing patterns. Somatosens Motor Res 6: 413-425.

Basbaum AI, Fields HL (1984) Endogenous pain control systems: brainstem spinal pathway and endorphin circuitry. Annu Rev Neurosci 7:309-338.

Bederson JB, Barbaro NM, Fields HL (1990) Hyperalgesia following naloxone-precipitated withdrawal from morphine is associated with increased on-cell activity in the rostral ventromedial medulla. Somatosens Motor Res 7:185-203.

Behbehani MM, Fields HL (1979) Evidence that an excitatory connection between the periaqueductal gray and nucleus raphe magnus mediates stimulation produced analgesia. Brain Res 170:85-93.

Beitz AJ, Shepard RD, Wells WE (1983) The periaqueductal grayraphe magnus projection contains somatostatin, neurotensin and serotonin but not cholecystokinin. Brain Res 261:132-137.

Bickel WK, Stitzer ML, Liebson IA, Bigelow GE (1988) Acute physical dependence in man: effects of naloxone after brief morphine exposure. J Pharmacol Exp Ther 43:120-132.

Bozarth MA, Wise RA (1984) Anatomically distinct opiate receptor fields mediate reward and physical dependence. Science 224:516-517.

Cheng Z-F, Fields HL, Heinricher MM (1986) Morphine microinjected into the periaqueductal gray has differential effects on 3 classes of medullary neurons. Brain Res 375:57-65.

Dickenson AH, Oliveras J-L, Besson J-M (1979) Role of the nucleus raphe magnus in opiate analgesia as studied by the microinjection technique in the rat. Brain Res 170:95-111.

Donnerer J (1989) Primary sensory neurones and naloxone-precipitated withdrawal. Br J Pharmacol 96:767-772.

Eide PK, Rosland JH (1989) The role of tail skin temperature in the facilitation of the tail-flick reflex after spinal transection or interference with descending serotonergic neurotransmission. Acta Physiol Scand 135:427-433.

Fields HL (1985) Neural mechanisms of opiate analgesia. In: Advances in pain research and therapy, Vol 9 (Fields HL, et al., eds), pp 479-486. New York: Raven.

Fields HL, Vanegas H, Hentall ID, Zorman G (1983) Evidence that 
disinhibition of brainstem neurones contributes to morphine analgesia. Nature 306:684-686.

Fields HL, Barbaro NM, Heinricher MM (1988) Brainstem neuronal circuitry underlying the antinociceptive action of opiates. In: Progress in brain research, Vol 77 (Fields HL, Besson J-M, eds), pp 245-257. Amsterdam: Elsevier.

Heinricher MM, Barbaro NM, Fields HL (1989) Putative nociceptive modulating neurons in the rostral ventromedial medulla of the rat: firing of on- and off-cells is related to nociceptive responsiveness. Somatosens Motor Res 6:427-439.

Heishman SJ, Stitzer ML, Bigelow GE, Liebson IA (1989) Acute physical dependence in postaddict humans: naloxone dose effects after brief morphine exposure. J Pharmacol Exp Ther 240:127-134.

Jaffe JH (1985) Drug addiction and drug abuse. In: The pharmacological basis of therapeutics, 7th ed (Gilman et al., eds). New York: Macmillan.

Jensen TS, Yaksh TL (1984) Spinal monamine and opiate systems partly mediate the antinociceptive cffects produced by glutamate at brainstem sites. Brain Res 321:287-297.

Jensen TS, Yaksh TL (1986) Comparison of antinociceptive action of morphine in the periaqueductal gray, medial, and paramedial medulla in rat. Brain Res 363:99-113.

Katovich MJ, Simpkins JW, Barney CC (1987) Alpha-adrenergic mediation of the tail skin temperature response to naloxone in morphine dependent rats. Brain Res 426:55-61.

Kayan S, Woods LA, Mitchell CL (1971) Morphine-induced hyperalgesia in rats tested on the hot plate. J Pharmacol Exp Ther 177: 509-513.

Kim DH, Barbaro NM, Fields HL (1990) Morphine analgesia and dependence: immediate onset of two opposing, dose related processes. Brain Res 516:37-40.

Kosersky DS, Harris RA, Harris LS (1974) Naloxone-precipitatcd jumping activity in mice following the acute administration of morphine. Eur J Pharmacol 26:122-124.

Light AR, Casale EJ, Menetrey DM (1986) The effects of focal stimulation in nucleus raphe magnus and periaqueductal gray on intracellularly recorded neurons in spinal laminae I and II. J Neurophysiol 56:555-571.

Ness TJ, Gebhart GF (1986) Centrifugal modulation of the rat tail flick reflex evoked by graded noxious heating of the tail. Brain Res 386:41-52.

Oliveras JL, Vos B, Martin G, Montagne J (1989) Electrophysiological properties of ventromedial medulla neurons and response to noxious and non-noxious stimuli in the awake, freely moving rat: a single unit study. Brain Res 486:1-14.

Proudfit HK (1980) Reversible inactivation of raphe magnus neurons: effect on nociceptive threshold and morphine-induced analgesia. Brain Res 201:459-464.

Proudfit HK, Anderson EG (1975) Morphine analgesia: blockade by raphe magnus lesions. Brain Res 98:612-618.

Ritzman RF (1981) Opiate dependence following acute injections of morphine and naloxone: the assessment of various withdrawal signs. Pharmacol Biochem Behav 14:575-577.

Sandkuhler J, Gebhart GF (1984) Characterization of inhibition of a spinal nociceptive reflex by stimulation medially and laterally in the midbrain and medulla in the pentobarbital-anesthetized rat. Brain Res 305:67-76.

Satoh M, Oku R, Akaike A (1983) Analgesia produced by microinjection of L-glutamate into the rostral ventromedial bulbar nuclei of the rat and its inhibition by intrathecal alpha-adrenergic blocking agents. Brain Res 261:361-364.

Wei E, Loh H (1976) Physical dependence on opiate-like peptides. Science 193:1262-1263.

Wilcox RE, Jamikula JA, Levitt RA (1979) Periaqueductal grey naloxone microinjection in morphine-dependent rats: hyperalgesia without "classical" withdrawal. Neuropharmacology 18:639-641.

Willis WD (1988) Anatomy and physiology of descending control of nociceptive responses of dorsal horn neurons: comprehensive review. In: Progress in brain research, Vol 77 (Fields HL, Benson JL, eds), pp 1-29. Amsterdam: Elsevier.

Yaksh TL (1981) Spinal opiate analgesia: characteristics and principles of action. Pain 11:293-346.

Yaksh TL, Al-Rodhan NRF, Jensen TS (1988) Site of action of opiates in production of analgesia. In: Progress in brain research, Vol 77 (Ficlds HL, Besson J-M, eds). Amsterdam: Elsevier.

Yeung JC, Rudy TA (1980) Multiplicative interaction between narcotic agonists expressed at spinal and supraspinal sites of antinociceptive action as revealed by concurrent intrathecal and intracerebroventricular injections of morphine. J Pharmacol Exp Ther 215: 633-642.

Zhuo M, Gebhart GF (1990) Characterization of descending facilitation and inhibition from the nuclei reticularis gigantocellularis (NGC) and gigantocellularis pars-alpha in the rat. Pain [Suppl] 5:S439.

Zorman G, Hentall ID, Adams JE, Fields HL (1981) Naloxone-reversible analgesia produced by micro-stimulation in the rat medulla. Brain Res 219:137-148. 